\title{
Glycemic status affects the severity of coronavirus disease 2019 in patients with diabetes mellitus: an observational study of CT radiological manifestations using an artificial intelligence algorithm
}

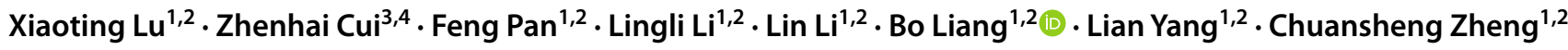

Received: 28 August 2020 / Accepted: 6 December 2020 / Published online: 8 January 2021

(c) Springer-Verlag Italia S.r.l., part of Springer Nature 2021

\begin{abstract}
Aims Increasing evidence suggests that poor glycemic control in diabetic individuals is associated with poor coronavirus disease 2019 (COVID-19) pneumonia outcomes and influences chest computed tomography (CT) manifestations. This study aimed to explore the impact of diabetes mellitus (DM) and glycemic control on chest CT manifestations, acquired using an artificial intelligence (AI)-based quantitative evaluation system, and COVID-19 disease severity and to investigate the association between CT lesions and clinical outcome.

Methods A total of 126 patients with COVID-19 were enrolled in this retrospective study. According to their clinical history of DM and glycosylated hemoglobin (HbA1c) level, the patients were divided into 3 groups: the non-DM group (Group 1); the well-controlled blood glucose (BG) group, with HbA1c $<7 \%$ (Group 2); and the poorly controlled BG group, with $\mathrm{HbA1c} \geq 7 \%$ (Group 3). The chest CT images were analyzed with an AI-based quantitative evaluation system. Three main quantitative CT features representing the percentage of total lung lesion volume (PLV), percentage of ground-glass opacity volume (PGV) and percentage of consolidation volume (PCV) in bilateral lung fields were used to evaluate the severity of pneumonia lesions.

Results Patients in Group 3 had the highest percentage of severe or critical illness, with 12 (32\%) cases, followed by 6 $(11 \%)$ and $7(23 \%)$ cases in Groups 1 and 2, respectively $(p=0.042)$. The composite endpoints, including death or using mechanical ventilation or admission to the intensive care unit (ICU), were $3(5 \%), 5(16 \%)$ and 10 (26\%) in Groups 1, 2 and 3, respectively $(p=0.013)$. The PLV, PGV and PCV in bilateral lung fields were significantly different among the three groups (all $p<0.001$ ): the median PLVs were 12.5\% (Group 3), 3.8\% (Group 2) and 2.4\% (Group 1); the median PGVs were $10.2 \%$ (Group 3), 3.6\% (Group 2) and 1.9\% (Group 1); and the median PCVs were 1.8\% (Group 3), 0.3\% (Group 2) and $0.1 \%$ (Group 1). In the linear regression analyses, which were adjusted for age, sex, BMI, and comorbidities, HbA1c remained positively associated with $\operatorname{PLV}(\beta=0.401, p<0.001), \operatorname{PGV}(\beta=0.364, p=0.001)$ and PCV $(\beta=0.472, p<0.001)$; this relationship was also observed between fasting blood glucose (FBG) and the three CT quantitative parameters. In the logistic regression analyses, PLV [OR $1.067(1.032,1.103)]$, PGV [OR $1.076(1.034,1.120)]$ and PCV [OR $1.280(1.110$, 1.476)] levels were independent predictors of the composite endpoints, as well as the areas under the ROC (AUCs) for PLV [AUC $0.796(0.691,0.900)]$, PGV [AUC $0.783(0.678,0.889)$ ] and PCV [AUC $0.816(0.722,0.911)$ ]; the ORs were still significant for CT lesions after adjusting for age, sex and poorly controlled diabetes.

Conclusions Increased blood glucose level was correlated with the severity of lung involvement, as evidenced by certain chest CT parameters, and clinical prognosis in diabetic COVID-19 patients. There was a positive correlation between blood glucose level (both HbA1c and FBG) on admission and lung lesions. Moreover, the CT lesion severity by AI quantitative analysis was correlated with clinical outcomes.
\end{abstract}

Managed by Massimo Porta.

Xiaoting Lu and Zhenhai Cui have contributed equally to this work.

Extended author information available on the last page of the article 
Keywords COVID-19 $\cdot$ DM $\cdot$ Blood glucose $\cdot$ CT $\cdot$ AI

\section{Introduction}

The coronavirus disease 2019 (COVID-19) pandemic resulted in 21,294,845 confirmed infections and 761,779 deaths as of August 16, 2020, according to the situation report of the World Health Organization (WHO) [1]. Previous studies suggested that 14-20\% of COVID-19 patients had diabetes, which was associated with increased severity and mortality [2-9].

To date, general clinical features, laboratory manifestations, and qualitative chest CT findings have been reported in diabetes patients with COVID-19; however, the relationship between glycemic status and lung CT severity remains understudied $[4,5]$. This study aimed to explore the impact of diabetes mellitus (DM) and blood glucose status on chest CT manifestations in COVID-19 patients using an artificial intelligence (AI)-based quantitative evaluation system to provide preliminary insight into COVID-19 comorbid with diabetes from a radiological perspective.

\section{Materials and methods}

This study was approved by the Ethics of Committees of Union Hospital, Tongji Medical College, Huazhong University of Science and Technology, and in accordance with the 1964 Declaration of Helsinki and its later amendments or comparable ethical standards. Informed consent was waived for this retrospective study.

\section{Study participants and design}

This retrospective study reviewed the clinical records of 480 patients with COVID-19 who were admitted to Union Hospital of Tongji Medical College in Wuhan, China, from January 20 to February 25, 2020; 136 patients with glycosylated hemoglobin (HbA1c) and fasting blood glucose (FBG) examination data were enrolled. According to the Guidelines for the Diagnosis and Treatment of COVID-19 Pneumonia published by the National Health Commission of the People's Republic of China (7th edition, in Chinese), all COVID-19 patients met the following criteria: (1) a history of travel to or residence in Wuhan or exposure to individuals with fever, (2) fever or other respiratory symptoms, (3) typical CT image abnormities indicative of viral pneumonia, and (4) positive real-time reverse transcriptase polymerase chain reaction (rRT-PCR) results for SARS-CoV-2 RNA from throat-swab specimens obtained from the upper respiratory tract at admission. All the patients enrolled in this study met all of the criteria mentioned above. According to the guidelines, disease cases was classified as mild, moderate, severe or critical. The diagnosis criteria are as follows: (1) mild cases: mild clinical symptoms and negative chest imaging examination findings; (2) moderate cases: fever or other respiratory symptoms, typical COVID-19 pneumonia findings on chest imaging examinations; (3) severe cases: the presence of any of the following criteria: (1) polypnea, a respiratory rate $\geq 30$ breaths/min; (2) oxygen saturation $\leq 93 \%$ in a resting state; (3) an arterial oxygen partial pressure/fractional inspired oxygen ratio $\left(\mathrm{PaO}_{2} / \mathrm{FiO}_{2}\right.$ ratio $) \leq 300 \mathrm{mmHg}$; and (4) lung involvement developing $>50 \%$ within $24-48 \mathrm{~h}$; (4) critical cases: any of the following criteria: (1) respiratory failure requiring mechanical ventilation; (2) shock; and (3) other organ failure with the need for intensive care unit (ICU) treatment [10].

The DM patients were defined as those who had at least one of the following conditions: (1) a history of DM and treatment with regular diabetes-specific hypoglycemic agents or insulin, (2) a fasting blood glucose concentration greater than $7.0 \mathrm{mmol} / \mathrm{L}(126 \mathrm{mg} / \mathrm{dL})$ measured at 2 different time points, and (3) an $\mathrm{HbAlc}$ level greater than $6.5 \%$ (48 $\mathrm{mmol} / \mathrm{mol}$ ) [11]. All the patients in this study had type 2 diabetes.

A total of 79 patients were identified as DM patients, and the remaining 57 were non-DM patients (Group 1). To avoid interference by concurrent pulmonary diseases with diagnostic accuracy, DM patients with lung cancer (1 patient), atelectasis (1 patient) and tuberculosis (3 patients) were excluded from this study. CT images with poor quality (5 patients) that were not suitable for AI evaluation were also excluded. According to the level of HbA1c within 3 days of hospital admission, the DM patients were divided into the following two groups, with a cutoff value of $7 \%$ [12]: the well-controlled BG group (Group 2, $n=31$ ), with $\mathrm{HbA} 1 \mathrm{c}<7 \%(53 \mathrm{mmol} / \mathrm{mol})$; and the poorly controlled BG group (Group 3, $n=38)$, with $\mathrm{HbAlc} \geq 7 \%(53 \mathrm{mmol} / \mathrm{mol})$. Finally, a cohort of 126 patients was included in the analysis. The detailed inclusion and exclusion processes are shown in Fig. 1.

Data regarding baseline demographics, laboratory results within 3 days of hospital admission, complications, diabetes treatment and clinical outcomes were collected. The composite endpoint was used to describe the clinical prognosis of the three groups, and it was defined as the composite of death or using mechanical ventilation or admission to the ICU. Patients were classified according to their body mass index (BMI) into four categories: underweight $(<18.5 \mathrm{~kg} /$ $\mathrm{m}^{2}$ ), healthy weight (from 18.5 to $<25 \mathrm{~kg} / \mathrm{m}^{2}$ ), overweight (from 25 to $\left.<30 \mathrm{~kg} / \mathrm{m}^{2}\right)$, and obese $\left(\geq 30 \mathrm{~kg} / \mathrm{m}^{2}\right)$. The 
From January 20 to February 25, 2020, a total of 480 patients with RT- PCR confirmed COVID-19 infection were included

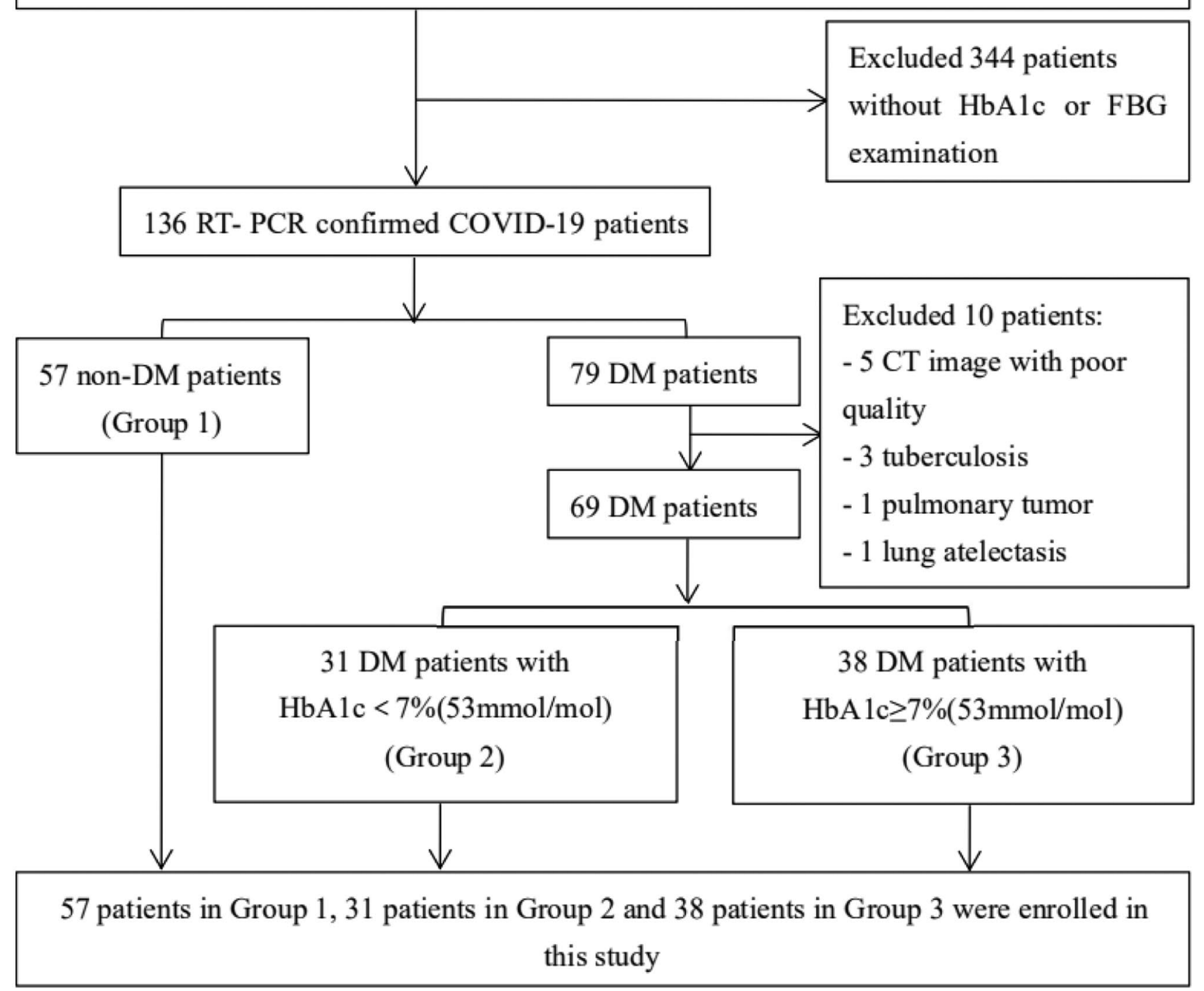

Fig. 1 Flowchart of study selection

duration of hospitalization and illness days (from symptom onset to discharge) were compared among the three groups to explore the impact of glycemic status on the COVID-19 course. The discharge criteria conformed with the Guidelines for Diagnosis and Management of COVID-19 (7th edition, in Chinese), released by the National Health Commission of China [10].

\section{CT protocol and radiographic evaluation}

A chest CT scan was obtained with the patient in the supine position and was performed at end inspiration without contrast agents. Two commercial multidetector CT scanners
(Philips Ingenuity Core128, Philips Medical Systems, Best, the Netherlands; SOMATOM Definition AS, Siemens Healthineers, Germany) were used, and patients were screened using either of them. All the patients were instructed on breath-holding to minimize motion artifacts. The range of the chest CT scans extended from the upper level of the thoracic inlet to the inferior level of the costophrenic angle. Standard lung algorithm settings are as follows: $120 \mathrm{kVp}$ and automatic tube current (180-400 mA); hybrid iterative reconstruction technique (iDose level 5, Philips Medical Systems, the Netherlands) or a pulmonary B70F kernel and a mediastinal B30f kernel (Siemens Healthineers, Germany); detector, $64 \mathrm{~mm}$; rotation time, 
$0.35 \mathrm{~s}$; section thickness, $1.5 \mathrm{~mm}$; collimation, $0.625 \mathrm{~mm}$; pitch, 1.5 ; and matrix, $512 \times 512$. Then, the images were reconstructed and transmitted to the workstation and picture archiving and communication systems (PACS) for multiplanar reconstruction postprocessing.

The CT image features were automatically calculated by a specialized quantitative CT evaluation system for COVID19 (YT-CT-Lung, YITU Healthcare Technology Co., Ltd., China), which has been used in clinical practice and scientific research $[13,14]$. The quantitative parameters of lung lesions included the total lung volume $\left(\mathrm{TV}, \mathrm{cm}^{3}\right)$, total lung lesion volume $\left(\mathrm{LV}, \mathrm{cm}^{3}\right)$, ground-glass opacity volume $(\mathrm{GV}$, $\mathrm{cm}^{3}$ ), consolidation volume $\left(\mathrm{CV}, \mathrm{cm}^{3}\right)$, percentage of total lung lesion volume (PLV), percentage of ground-glass opacity volume (PGV), and percentage of consolidation volume $(\mathrm{PCV})$.

\section{Statistical analysis}

Qualitative data were expressed as frequency rates and percentages (\%), and quantitative data were expressed as medians (IQRs). Qualitative data were compared among the three groups using the chi-square test or Fisher's exact test, and quantitative data were analyzed using the Kruskal-Wallis test, followed by the Dunn-Bonferroni post hoc method. Spearman correlation and linear regression analyses were performed to estimate the relationships between $\mathrm{HbAlc}$ or FBG and CT radiological manifestations as captured by AI analysis. Regarding the severity of pulmonary lesions and clinical outcomes, logistic regression was used as the classifier to build the predictive model after adjusting for age, sex and poorly controlled diabetes (Group 3 vs. other groups), and the discrimination performance was quantified by the value of area under the ROC curve (AUC). All statistical analyses were performed using IBM SPSS Statistics Software (version 24; IBM, New York, USA). A two-sided $p$ value $<0.05$ was considered statistically significant.

\section{Results}

\section{General characteristics of study subjects}

The median age of the patients was 60.4 years (IQR $55.0-68.1$ years), the number of men was $73(58 \%)$, and the number of women was $53(42 \%)$. The median age and sex distribution were not significantly different $(p>0.05$ each) among the three groups. Fever (73\%), cough (58\%) and weakness (39\%) were the most common onset symptoms in this study. The most common underlying comorbidities were hypertension (42\%) and cardiovascular disease (12\%). The clinical severity classification of COVID-19, the duration of hospitalization days and the duration of illness were significantly different among the three groups [Group 1 vs. 2 vs. $3,6(11 \%)$ vs. $7(23 \%)$ vs. $12(32 \%), p=0.042$; $19.0(12.0-28.0)$ vs. $20.0(11.5-29.5)$ vs. $26.0(18.0-37.0)$, $p=0.037$ and $40.0(32.0-47.0)$ vs. $40.0(30.0-49.0)$ vs. 44.5 (38.8-53.0), $p=0.049$, respectively].

The median HbA1c level was 6.3 (IQR 5.6-7.5\%) [45 (IQR $38-58 \mathrm{mmol} / \mathrm{mol}$ )] in the whole cohort and 5.5 (IQR 5.3-5.9\%) [37 (IQR 34-41 mmol/mol)], 6.5 (IQR 6.2-6.7\%) [48 (IQR 44-50 mmol/mol)], and 8.4 (IQR 7.7-10.6\%) [68 (IQR 61-92 mmol/mol)] in Group 1, Group 2, and Group 3, respectively. The median FBG level was 6.1 (IQR 5.2-8.3) $\mathrm{mmol} / \mathrm{L}$ in the whole cohort and 5.2 (IQR 4.9-5.9) $\mathrm{mmol} / \mathrm{L}$, 6.6 (IQR 5.9-7.4) $\mathrm{mmol} / \mathrm{L}$, and 10.3 (IQR 7.8-14.1) $\mathrm{mmol} / \mathrm{L}$ in Group 1, Group 2, and Group 3, respectively. The median leukocyte count was $5.6\left(\right.$ IQR $4.6-7.0 \times 10^{9} / \mathrm{L}$ )

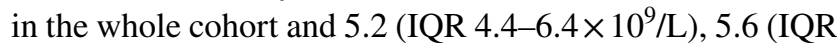
$\left.4.8-7.0 \times 10^{9} / \mathrm{L}\right)$ and $6.6\left(\mathrm{IQR} 4.8-8.2 \times 10^{9} / \mathrm{L}\right)$ in Group 1 , Group 2, and Group 3, respectively. CRP was notably higher in Group 3 than in the other two groups. The other laboratory results, including routine blood examination, hepatic and renal function, and serum lipid level results, were not significantly different among the three groups. The composite endpoints were $3(5 \%), 5(16 \%)$ and $10(26 \%)$ in Groups 1,2 and 3 , respectively $(p=0.013)$. All the data are summarized in Table 1.

\section{Chest CT manifestations}

Table 2 illustrates the characteristics of the CT scans analyzed by the AI system. The median time between symptom onset and CT scan was 15.0 days (IQR 8.3-30.0), which showed no significant differences among the three groups. While the total lung volume was similar among the three groups, LV, GV, CV, PLV, PGV, and PCV all showed significant differences among the three groups [the medians(IQRs) in Group 1, 2 and 3: $\mathrm{LV}\left(\mathrm{cm}^{3}\right)$ : 93.1 (25.1-275.7) vs. $115.5(58.9-309.4)$ vs. $438.5(159.9-1150.5) ; \mathrm{GV}\left(\mathrm{cm}^{3}\right)$ : $69.3(22.5-222.6)$ vs. $114.4(56.1-271.0)$ vs. 355.0 (144.6-933.6); $\mathrm{CV}\left(\mathrm{cm}^{3}\right): 5.0(0.7-35.8)$ vs. $10.0(3.4-17.5)$ vs. 73.1 (12.5-175.3); $\operatorname{PLV}(\%): 2.4(0.6-5.8)$ vs. 3.8 (1.6-9.5) vs. 12.5 (4.1-34.1); $\mathrm{PGV}(\%): 1.9(0.5-5.2)$ vs. 3.6 (1.4-7.3) vs. $10.2(4.0-26.3)$; $\mathrm{PCV}(\%): 0.1(0.0-0.6)$ vs. 0.3 $(0.1-0.7)$ vs. $1.8(0.3-5.7)$; respectively; $p<0.001$ for all)]. All the CT quantitative parameters were not significantly different between Group 1 and Group 2. Three cases of lung lesions as indicated by AI quantitative analysis are shown in Fig. 2.

\section{The association between CT manifestations and glycemic control}

The association between glycemic control (both HbA1c and FBG on admission) and CT manifestations is displayed 
Table 1 General characteristics of study subjects

\begin{tabular}{|c|c|c|c|c|c|}
\hline & $\begin{array}{l}\text { All patients } \\
n=126\end{array}$ & $\begin{array}{l}\text { Group } 1 \\
n=57\end{array}$ & $\begin{array}{l}\text { Group } 2 \\
n=31\end{array}$ & $\begin{array}{l}\text { Group } 3 \\
n=38\end{array}$ & $p$ value \\
\hline \multicolumn{6}{|l|}{ General demographics } \\
\hline Age (years) & $60.4(55.0-68.1)$ & $60.3(50.3-65.8)$ & $60.0(55.0-71.0)$ & $62.0(57.0-70.5)$ & 0.220 \\
\hline Male $(\%)$ & $73(58 \%)$ & $34(61 \%)$ & $14(45 \%)$ & $25(66 \%)$ & 0.194 \\
\hline Ever smoking $(N, \%)$ & $16(13 \%)$ & $7(13 \%)$ & $4(13 \%)$ & $5(13 \%)$ & 1.000 \\
\hline \multicolumn{6}{|l|}{ Signs and symptoms } \\
\hline Fever & $91(73 \%)$ & $45(80 \%)$ & $20(65 \%)$ & $26(68 \%)$ & 0.203 \\
\hline Cough & $73(58 \%)$ & $33(59 \%)$ & $19(61 \%)$ & $21(55 \%)$ & 0.895 \\
\hline Sputum & $24(19 \%)$ & $14(25 \%)$ & $6(19 \%)$ & $4(11 \%)$ & 0.215 \\
\hline Chest tightness & $32(26 \%)$ & $14(25 \%)$ & $9(29 \%)$ & $9(24 \%)$ & 0.899 \\
\hline Dyspnea & $21(17 \%)$ & $10(18 \%)$ & $7(23 \%)$ & $4(11 \%)$ & 0.420 \\
\hline Vomiting & $10(8 \%)$ & $4(7 \%)$ & $1(3 \%)$ & $5(13 \%)$ & 0.334 \\
\hline Diarrhea & $16(13 \%)$ & $6(11 \%)$ & $3(10 \%)$ & $7(18 \%)$ & 0.491 \\
\hline Weakness & $49(39 \%)$ & $21(38 \%)$ & $10(32 \%)$ & $18(47 \%)$ & 0.412 \\
\hline Muscular soreness & $39(31 \%)$ & $19(34 \%)$ & $9(29 \%)$ & $11(29 \%)$ & 0.881 \\
\hline Body mass index (BMI, $\left.\mathrm{kg} / \mathrm{m}^{2}\right)$ & $24.2(22.3-26.7)$ & $24.6(22.0-26.1)$ & $23.8(22.3-27.5)$ & $24.5(22.4-27.3)$ & 0.801 \\
\hline Weight status & & & & & 0.683 \\
\hline Underweight & $1(1 \%)$ & $1(4 \%)$ & $0(0 \%)$ & $0(0 \%)$ & \\
\hline Healthy weight & $47(58 \%)$ & $14(56 \%)$ & $16(67 \%)$ & $17(53 \%)$ & \\
\hline Overweight & $26(32 \%)$ & $9(36 \%)$ & $6(25 \%)$ & $11(34 \%)$ & \\
\hline Obesity & $7(9 \%)$ & $1(4 \%)$ & $2(8 \%)$ & $4(13 \%)$ & \\
\hline \multicolumn{6}{|l|}{ Blood pressure (mmHg) } \\
\hline Systolic pressure & $135.0(120.0-145.0)$ & $133.0(120.0-143.0)$ & $136.5(121.5-143.0)$ & $136.5(120.3-149.0)$ & 0.786 \\
\hline Diastolic pressure & $83.0(74.3-91.8)$ & $81.0(73.0-94.0)$ & $81.0(73.5-90.0)$ & $85.0(78.0-95.0)$ & 0.517 \\
\hline \multicolumn{6}{|l|}{ Comorbidities } \\
\hline Any & $68(54 \%)$ & $27(48 \%)$ & $17(55 \%)$ & $24(63 \%)$ & 0.371 \\
\hline Hypertension & $53(42 \%)$ & $19(34 \%)$ & $15(48 \%)$ & $19(50 \%)$ & 0.233 \\
\hline Cardiovascular disease & $15(12 \%)$ & $7(13 \%)$ & $2(6 \%)$ & $6(16 \%)$ & 0.498 \\
\hline Cerebrovascular disease & $7(6 \%)$ & $3(5 \%)$ & $1(3 \%)$ & $3(8 \%)$ & 0.786 \\
\hline Chronic pulmonary disease & $7(6 \%)$ & $3(5 \%)$ & $2(6 \%)$ & $2(5 \%)$ & 1.000 \\
\hline Hepatitis or liver cirrhosis & $2(2 \%)$ & $0(0 \%)$ & $1(3 \%)$ & $1(3 \%)$ & 0.501 \\
\hline Chronic renal failure & $3(2 \%)$ & $1(2 \%)$ & $1(3 \%)$ & $1(3 \%)$ & 1.000 \\
\hline Malignancy & $9(7 \%)$ & $3(5 \%)$ & $3(10 \%)$ & $3(8 \%)$ & 0.748 \\
\hline Clinical classifications & & & & & 0.042 \\
\hline Moderate cases & $101(80 \%)$ & $51(89 \%)$ & $24(77 \%)$ & $26(68 \%)$ & \\
\hline Severe or critical cases & $25(20 \%)$ & $6(11 \%)$ & $7(23 \%)$ & $12(32 \%)$ & \\
\hline Duration of hospitalization (days) & $21.0(13.0-31.0)$ & $19.0(12.0-28.0)$ & $20.0(11.5-29.5)$ & $26.0(18.0-37.0)$ & 0.037 \\
\hline Duration of illness (days) & $42.0(34.0-49.0)$ & $40.0(32.0-47.0)$ & $40.0(30.0-49.0)$ & $44.5(38.8-53.0)$ & 0.049 \\
\hline \multicolumn{6}{|l|}{ Laboratory results } \\
\hline Fast blood glucose $(\mathrm{mmol} / \mathrm{L})$ & $6.1(5.2-8.3)$ & $5.2(4.9-5.9)$ & $6.6(5.9-7.4)$ & $10.3(7.8-14.1)$ & 0.000 \\
\hline HbAlc $(\%)$ & $6.3(5.6-7.5)$ & $5.5(5.3-5.9)$ & $6.5(6.2-6.7)$ & $8.4(7.7-10.6)$ & 0.000 \\
\hline $\mathrm{HbAlc}(\mathrm{mmol} / \mathrm{mol})$ & $45(38-58)$ & $37(34-41)$ & $48(44-50)$ & $68(61-92)$ & \\
\hline Leukocyte count, $\times 10^{9} / \mathrm{L}$ & $5.6(4.6-7.0)$ & $5.2(4.4-6.4)$ & $5.6(4.8-7.0)$ & $6.6(4.8-8.2)$ & 0.010 \\
\hline Lymphocyte count, $\times 10^{9} / \mathrm{L}$ & $1.4(1.1-1.9)$ & $1.5(1.1-1.9)$ & $1.4(1.1-1.8)$ & $1.2(0.8-1.9)$ & 0.640 \\
\hline Platelet count, $\times 10^{9} / \mathrm{L}$ & $203.0(151.0-252.0)$ & $196.0(151.0-237.0)$ & $207.0(151.0-245.0)$ & $221.0(149.5-293.0)$ & 0.523 \\
\hline Hemoglobin, $\mathrm{ng} / \mathrm{mL}$ & $127.0(114.0-138.0)$ & $129.0(112.0-142.0)$ & $121.0(112.0-129.0)$ & $129.0(119.0-141.5)$ & 0.119 \\
\hline C-reactive protein, $\mathrm{mg} / \mathrm{L}$ & $5.0(1.7-25.0)$ & $3.0(0.6-12.5)$ & $5.4(2.5-11.4)$ & $9.8(3.6-77.4)$ & 0.009 \\
\hline Alanine aminotransferase (U/L) & $32.0(20.0-59.0)$ & $37.0(21.0-66.3)$ & $26.0(18.0-37.0)$ & $32.5(20.0-57.0)$ & 0.078 \\
\hline Aspartate aminotransferase (U/L) & $26.0(19.0-40.5)$ & $29.5(19.3-43.8)$ & $24.0(17.0-32.0)$ & $25.0(20.5-44.0)$ & 0.107 \\
\hline Total bilirubin, $\mu \mathrm{mol} / \mathrm{L}$ & $10.8(7.8-13.8)$ & $10.7(7.8-13.7)$ & $10.7(9.0-13.3)$ & $11.2(7.5-15.7)$ & 0.803 \\
\hline
\end{tabular}


Table 1 (continued)

\begin{tabular}{|c|c|c|c|c|c|}
\hline & $\begin{array}{l}\text { All patients } \\
n=126\end{array}$ & $\begin{array}{l}\text { Group } 1 \\
n=57\end{array}$ & $\begin{array}{l}\text { Group } 2 \\
n=31\end{array}$ & $\begin{array}{l}\text { Group } 3 \\
n=38\end{array}$ & $p$ value \\
\hline Albumin, g/L & $35.1(30.8-40.2)$ & $36.2(33.1-40.7)$ & $35.3(31.3-38.8)$ & $33.3(29.4-39.6)$ & 0.124 \\
\hline Blood urea nitrogen $(\mathrm{mmol} / \mathrm{L})$ & $5.1(4.0-6.7)$ & $4.8(4.0-5.9)$ & $5.7(4.3-7.2)$ & $5.5(3.9-8.6)$ & 0.156 \\
\hline Serum creatinine (ummol/L) & $67.0(56.7-77.7)$ & $67.3(56.9-75.6)$ & $66.1(56.4-79.3)$ & $68.5(56.3-80.5)$ & 0.905 \\
\hline Blood uric acid (ummol/L) & $287.8(216.4-356.4)$ & $296.4(221.2-394.3)$ & $292.2(242.3-349.9)$ & $256.6(173.2-325.1)$ & 0.139 \\
\hline Total cholesterol (mmol/L) & $4.5(3.5-5.2)$ & $4.7(3.6-5.3)$ & $4.0(2.9-5.2)$ & $4.3(3.5-5.1)$ & 0.445 \\
\hline Triglyceride (mmol/L) & $1.5(1.1-2.2)$ & $1.5(1.0-2.1)$ & $1.4(1.0-2.2)$ & $1.8(1.1-2.7)$ & 0.541 \\
\hline HDL-cholesterol (mmol/L) & $1.0(0.8-1.2)$ & $1.0(0.8-1.2)$ & $1.1(0.8-1.3)$ & $0.9(0.7-1.1)$ & 0.153 \\
\hline LDL-cholesterol (mmol/L) & $2.7(1.9-3.2)$ & $2.9(2.3-3.4)$ & $2.1(1.7-3.1)$ & $2.4(1.9-2.9)$ & 0.076 \\
\hline \multicolumn{6}{|l|}{ Treatment and outcomes } \\
\hline Treatment of diabetes & & & & & 0.180 \\
\hline Lifestyle intervention & - & - & $17(55 \%)$ & $16(42 \%)$ & \\
\hline Oral hypoglycemic agent (OHA) & - & - & $11(35 \%)$ & $11(29 \%)$ & \\
\hline Insulin + OHA & - & - & $1(3 \%)$ & $8(21 \%)$ & \\
\hline Insulin & - & - & $2(6 \%)$ & $3(8 \%)$ & \\
\hline Metformin & - & - & $9(29 \%)$ & $9(24 \%)$ & 0.409 \\
\hline DPP-4 inhibitors & - & - & $3(10 \%)$ & $2(5 \%)$ & 0.403 \\
\hline Use of corticosteroid & $28(22 \%)$ & $9(16 \%)$ & $7(23 \%)$ & $12(32 \%)$ & 0.197 \\
\hline Death & $4(3.2 \%)$ & $1(1.8 \%)$ & $1(3.2 \%)$ & $2(5.3 \%)$ & 0.813 \\
\hline Mechanical ventilation & $8(6.3 \%)$ & $1(1.8 \%)$ & $2(6.5 \%)$ & $5(13.2 \%)$ & 0.073 \\
\hline ICU admission & $10(7.9 \%)$ & $2(3.5 \%)$ & $3(9.7 \%)$ & $5(13.2 \%)$ & 0.202 \\
\hline Composite endpoints* & $18(14 \%)$ & $3(5 \%)$ & $5(16 \%)$ & $10(26 \%)$ & 0.013 \\
\hline
\end{tabular}

Quantitative data were presented as median (IQR), while the counting data were presented as count (percentage of the total)

Italic values indicate $P<0.05$

*Composite endpoints: The primary end point was a composite of death or using mechanical ventilation or admission to intensive care unit

Table 2 Characteristics of CT scan analyzed by AI systems among three groups

\begin{tabular}{|c|c|c|c|c|c|}
\hline & $\begin{array}{l}\text { All patients } \\
n=126\end{array}$ & $\begin{array}{l}\text { Group } 1 \\
n=57\end{array}$ & $\begin{array}{l}\text { Group } 2 \\
n=31\end{array}$ & $\begin{array}{l}\text { Group } 3 \\
n=38\end{array}$ & $p$ value \\
\hline $\begin{array}{l}\text { Onset of symptoms to CT } \\
\text { scan, days }\end{array}$ & $15.0(8.3-30.0)$ & $18.0(10.3-30.0)$ & $15.0(7.0-30.0)$ & $13.0(7.5-30.0)$ & 0.565 \\
\hline Total lung volume, $\mathrm{cm}^{3}$ & $3666.6(2904.8-4740.4)$ & $4032.4(3072.2-4903.1)$ & $3570.6(2858.6-4359.1)$ & $3495.5(2670.8-4653.2)$ & 0.111 \\
\hline $\begin{array}{l}\text { Total lung lesions volume, } \\
\mathrm{cm}^{3}\end{array}$ & $167.1(41.8-424.5)$ & $93.1(25.1-275.7)$ & $115.5(58.9-309.4)$ & $438.5(159.9-1150.5)$ & $<0.001$ \\
\hline GGO volume, $\mathrm{cm}^{3}$ & $145.1(37.8-370.7)$ & $69.3(22.5-222.6)$ & $114.4(56.1-271.0)$ & $355.0(144.6-933.6)$ & $<0.001$ \\
\hline Consolidation volume, $\mathrm{cm}^{3}$ & $12.4(2.7-69.0)$ & $5.0(0.7-35.8)$ & $10.0(3.4-17.5)$ & $73.1(12.5-175.3)$ & $<0.001$ \\
\hline $\begin{array}{l}\text { Percentage of total lung } \\
\text { lesions volume, } \%\end{array}$ & $4.6(1.2-11.5)$ & $2.4(0.6-5.8)$ & $3.8(1.6-9.5)$ & $12.5(4.1-34.1)$ & $<0.001$ \\
\hline $\begin{array}{l}\text { Percentage of GGO volume, } \\
\%\end{array}$ & $3.9(1.1-10.0)$ & $1.9(0.5-5.2)$ & $3.6(1.4-7.3)$ & $10.2(4.0-26.3)$ & $<0.001$ \\
\hline $\begin{array}{l}\text { Percentage of consolidation } \\
\text { volume, } \%\end{array}$ & $0.3(0.1-1.8)$ & $0.1(0.0-0.6)$ & $0.3(0.1-0.7)$ & $1.8(0.3-5.7)$ & $<0.001$ \\
\hline
\end{tabular}

Quantitative data were presented as median (IQR). No statistical differences were found between group 1 and group 2 analyzed by the DunnBonferroni post hoc method

in Table 3. In the linear regression analyses, $\mathrm{HbA} 1 \mathrm{c}$ and FBG were both associated with $\mathrm{LV}(\mathrm{HbA} 1 \mathrm{c}: \beta=0.392$; $p<0.001$; FBG: $\beta=0.361 ; p<0.001), \mathrm{GV}(\mathrm{HbA} 1 \mathrm{c}$ : $\beta=0.381 ; p<0.001 ;$ FBG $: \beta=0.350 ; p<0.001)$, CV(HbA1c: $\beta=0.314 ; p<0.001 ;$ FBG: $\beta=0.291$; $p=0.001), \operatorname{PLV}(\mathrm{HbA} 1 \mathrm{c}: \beta=0.432 ; p<0.001 ; \mathrm{FBG}$ : 
$\beta=0.413 ; p<0.001), \operatorname{PGV}($ HbA1c: $\beta=0.428 ; p<0.001$; FBG: $\beta=0.413 ; p<0.001)$ and PCV (HbA1c: $\beta=0.344$; $p<0.001$; FBG: $\beta=0.314 ; p<0.001)$, and the association remained after adjustment for age, sex, BMI, and comorbidities [LV(HbA1c: $\beta=0.330 ; p=0.003$; FBG: $\beta=0.359 ; p=0.001), \mathrm{GV}(\mathrm{HbA} 1 \mathrm{c}: \beta=0.289 ; p=0.009$; FBG: $\beta=0.323 ; p=0.003), \mathrm{CV}(\mathrm{HbA} 1 \mathrm{c}: \beta=0.437$; $p<0.001$; FBG: $\beta=0.436 ; p<0.001)$, PLV(HbA1c: $\beta=0.401 ; p<0.001 ; \mathrm{FBG}: \beta=0.446 ; p<0.001)$, PGV(HbA1c: $\beta=0.364 ; p=0.001 ; \mathrm{FBG}: \beta=0.421$; $p<0.001$ ) and PCV (HbA1c: $\beta=0.472 ; p<0.001$; FBG: $\beta=0.455 ; p<0.001)]$.Among them, PCV was best correlated with both $\mathrm{HbA} 1 \mathrm{c}$ and FBG.

\section{The association between CT manifestations and clinical outcomes}

Regarding the severity of pulmonary lesions and clinical outcomes, the logistic regression analyses showed that there were associations between LV (OR 1.002; 95\% CI 1.001-1.003; $p<0.001$ ), GV (OR 1.002; 95\% CI 1.001-1.003; $p<0.001), \mathrm{CV}$ (OR 1.007; 95\% CI $1.003-1.012 ; p=0.001), \mathrm{PLV}$ (OR 1.067; 95\% CI $1.032-1.103 ; p<0.001)$, PGV (OR 1.076; 95\% CI $1.034-1.120 ; p<0.001)$, PCV(OR 1.280; $95 \%$ CI $1.110-1.476 ; p=0.001)$ and the composite endpoint; the association remained after adjustment for age, sex and poorly controlled diabetes[LV (OR 1.002; 95\% CI 1.001-1.003; $p=0.003$ ), GV (OR 1.002; 95\% CI 1.000-1.003; $p=0.008)$, CV (OR 1.007; 95\% CI 1.002-1.012; $p=0.005)$, PLV (OR 1.057 ; 95\% CI 1.016-1.100; $p=0.006$ ), PGV (OR 1.061; 95\% CI 1.013-1.112; $p=0.013), \mathrm{PCV}(\mathrm{OR} 1.269 ; 95 \%$ CI 1.069-1.507; $p=0.006)]$; among them, PCV had the highest odds ratio (OR) of composite outcomes. The discrimination performance of the predictive model was quantified by the value of AUC[LV (0.786; 95\% CI 0.676-0.897; $p<0.001)$, GV (0.774; 95\% CI 0.662-0.886; $p<0.001)$, CV (0.811; 95\% CI 0.716-0.907; $p<0.001)$, PLV $(0.796 ; 95 \%$ CI $0.691-0.900 ; p<0.001)$, PGV (0.783; 95\% CI 0.678-0.889; $p<0.001)$, PCV $(0.816 ; 95 \%$ CI 0.722-0.911; $p<0.001)]$. All the data are summarized in Table 4.

\section{Discussion}

Chest CT plays an important role in COVID-19 screening, primary diagnosis, and evaluation [15-19]. However, traditional subjective CT evaluation of COVID-19 lung lesions suffers from interobserver variability and thus reduced diagnosis accuracy. Recently, artificial intelligence (AI) has shown promise in deriving quantitative CT features for disease monitoring and clinical outcome prediction in COVID-19 patients [13, 14, 20-22]. In this study, the baseline general demographics, such as age, sex, clinical symptoms, and underlying comorbidities, were not significantly different among the three groups. The median age in this study was 60.0 years in Group 2 and 62.0 years in Group 3, which were similar to those a previous study of DM patients [4, 5]. The cohort contained more males than females, and fever and cough were the first and second most common symptoms; both of these findings were consistence with previous reports including a more general patient population $[3,6]$. Among the three groups, patients in Group 3 had the highest percentages of severe and critical cases and clinical composite endpoints and the most hospitalization days and illness days. The leukocyte count among the three groups was significantly different, and the CRP level in Group 3 was obviously higher than those in the other two groups. These findings may indicate that poorly controlled BG patients with COVID-19 experienced more severe inflammatory reactions, which may indicate a worse prognosis and increased mortality, as reported previously in COVID-19 patients with DM [5, 23].

A previous study by Guo et al. reported that the CT severity score was higher in diabetic patients than in nondiabetic patients with COVID-19, but the severity score was evaluated with a semiquantitative scoring system, and the impact of blood glucose status on lung lesions was not studied [4]. Another study suggested that the incidence of bilateral lung lesions was similar between well-controlled BG patients and poorly controlled BG patients; however, lung lesions were not quantified [5]. As the first study to investigate the relationship between blood glucose status and COVID-19 pulmonary disease with AI analysis, this study showed that, compared to non-DM patients, DM patients with poorly controlled BG presented more severe lung lesions than those with well-controlled BG. In addition, HbA1c and FBG levels at admission were linearly positively correlated with lung lesion severity in diabetic COVID-19 patients. A study by Raoufi et al. suggested that CT differences were not found between well-controlled and poorly controlled DM patients [24]. This was not consistent with our study. There are three reasons that may explain the paradoxical findings between the two studies: (1) In the previous study, patients with well-controlled DM were significantly older than those with poorly controlled DM; the median age in the well-controlled group was 75.3 years, and that in the poorly controlled group was 62.2 years $(p<0.001)$. It is well known that old age is associated with a poor outcome in patients with COVID-19; consequently, older age in the well-controlled DM group may have been a confounding factor that caused the negative result in the previous study. (2) The previous study used the traditional CT severity score, which was a semiquantitative assessment method and was subject with large inter- and intraobserver variability. (3) There are ethnic and geographical differences between Chinese and Iranian populations. 

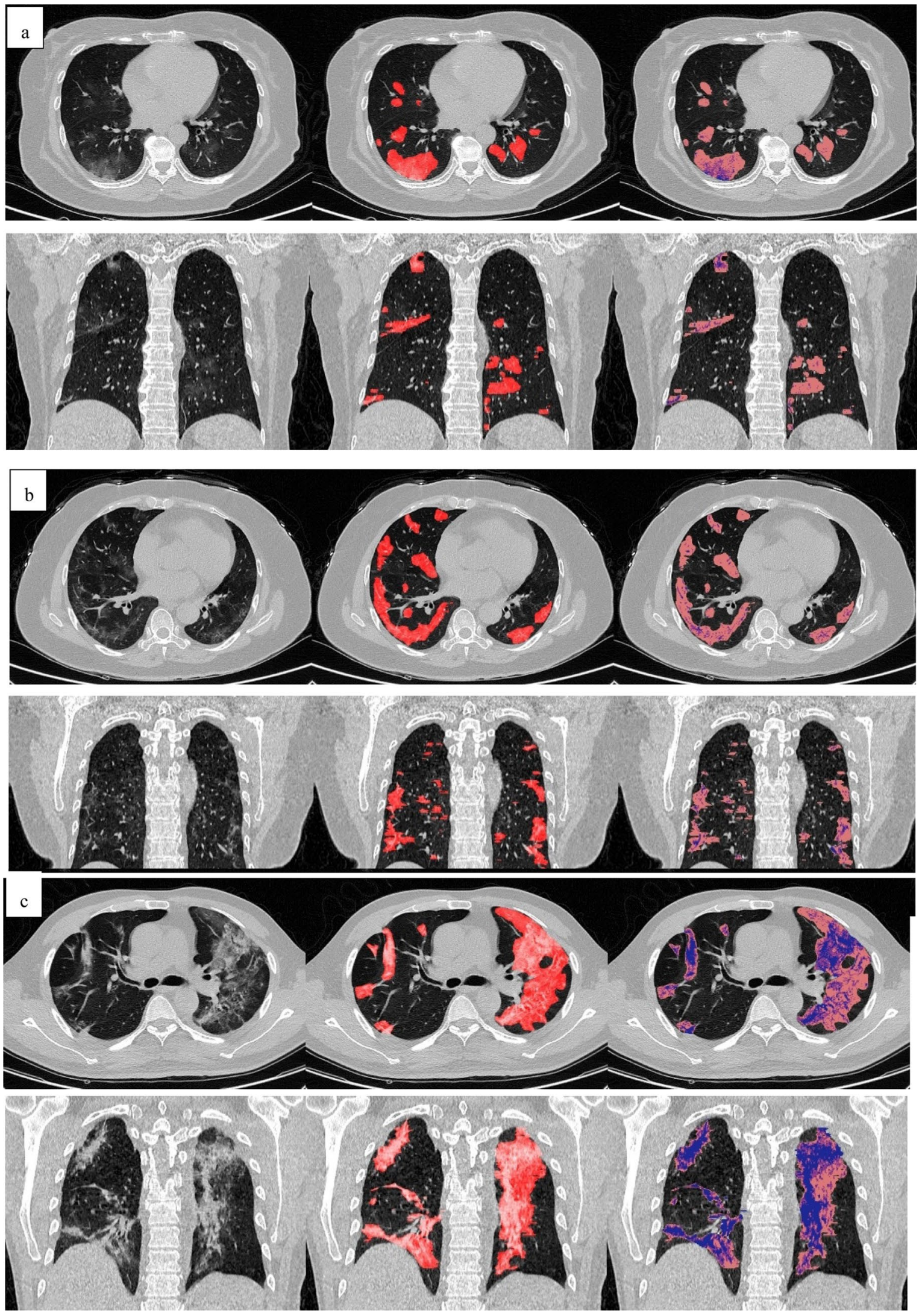
4Fig. 2 Cases of AI quantitative analysis of lung lesions: a A 67-yearold woman, with $\mathrm{HbA} 1 \mathrm{c} 6.0 \%$ and FBG $6.39 \mathrm{mmol} / \mathrm{L}$, no history of $\mathrm{DM}$, the lung lesions detected by the AI system and visualized as pseudo colors. Blue and pink pseudo colors representing groundglass opacity (GGO) and consolidation, respectively. The LV were the summation of GV and CV. The LV, GV, CV, PLV, PGV and PCV were $262.05 \mathrm{~cm}^{3}, 249.66 \mathrm{~cm}^{3}, 12.39 \mathrm{~cm}^{3}, 8.07 \%, 7.69 \%, 0.38 \%$, respectively; b A 57-year-old woman, with $\mathrm{HbA1c} 6.8 \%$ and FBG $6.63 \mathrm{mmol} / \mathrm{L}$, had a history of T2DM 8 years, taking metformin and acarbose to control blood glucose. The LV, GV, CV, PLV, PGV and PCV were $361.63 \mathrm{~cm}^{3}, 353.25 \mathrm{~cm}^{3}, 8.38 \mathrm{~cm}^{3}, 15.08 \%, 14.73 \%$, $0.35 \%$, respectively; c A 62 -year-old man, with HbA1c $9.9 \%$ and FBG $10.84 \mathrm{mmol} / \mathrm{L}$, had a history of T2DM 8 years, taking insulin Glargine and NovoMix30R to control blood glucose. The LV, GV, CV, PLV, PGV and PCV were $837.16 \mathrm{~cm}^{3}, 613.95 \mathrm{~cm}^{3}, 223.21 \mathrm{~cm}^{3}$, $28.32 \%, 20.77 \%, 7.55 \%$, respectively

The study by Iacobellis et al. suggested that admission hyperglycemia was the best predictor of radiographic severity of COVID-19 [25]. In our study, both FBG and $\mathrm{HbA1c}$ levels at admission were significantly predictive of the radiographic severity of COVID-19. These two studies shared some similarities while also noting some differences. Two reasons may explain the contradictory results: (1) the previous study had a smaller sample size than that in this study; (2) the previous study used chest radiograms (CXR) as a semiquantitative radiographic assessment method, while this study used chest CT examination with AI quantitative analysis. Chest $\mathrm{CT}$ is more accurate and precise than CXR.

Whether the HbA1c value is associated with a worse outcome in COVID-19 patients complicated with diabetes remains controversial. In a previous study, the HbA1c level in people with both type 1 and type 2 diabetes was an independent risk factor for COVID-19-related mortality [26]. In another study, a high HbA1c level was associated with inflammation, hypercoagulability, and low $\mathrm{SaO}_{2}$ in diabetic COVID-19 patients, eventually resulting in an increased mortality rate (27.7\%) [23]. These findings were consistent with those in our study.

The study reported by Cariou et al. indicated that $\mathrm{HbA} 1 \mathrm{c}$ was not associated with a worse outcome, which was discordant with the results of this study [27]. This discordance may be due to the following: (1) The clinical primary endpoint was different. In the previous study, the primary outcome and death were defined on day 7 , representing a shortterm prognosis rather than a long-term prognosis. This study analyzed the composite outcome during the whole period of hospitalization as the primary endpoint. (2) In the previous study, the $\mathrm{HbA} 1 \mathrm{c}$ value in some patients was determined in the 6 months prior and did not represent the blood glucose status at hospital admission. The HbA1c value in this study was obtained within 3 days of hospital admission. (3) The study subjects in the previous research were hospitalized COVID-19 patients, and a less-severe form of the disease was not generalized, while in this study, most of the patients had moderate illness, although all of them were hospitalized.

The pathologic mechanisms concerning the positive relationship between lung lesion severity and blood glucose levels in COVID-19 patients remain unclear. Elevated BG levels may increase viral replication and suppress the antiviral immune response [5, 28, 29]. Moreover, DM patients are more likely to be undernourished and are prone to develop a cytokine storm, which may eventually lead to rapid deterioration, than non-DM patients $[4,23]$. In addition, pulmonary dysfunction affecting lung volume, pulmonary diffusing capacity, respiration, bronchomotor tone, and neuroadrenergic bronchial innervation in non-COVID-19 patients with DM was previously reported [30]. All these factors may account for the tendency of serious lung damage in diabetic COVID-19 patients with poorly controlled BG.

There were some limitations in this study. First, the sample size was small, as only 126 inpatients were included in this study. Further large-sample studies will be needed to validate the findings of this study. In addition, as a singlecenter study, most of the cases in this study were of moderate severity, which led to selection bias. Moreover, because of the study design, regular CT was impractical for severe and critical cases; hence, the analysis of dynamic changes in lung CT lesions was not feasible in this study. Furthermore, some researchers consider that unknown/secondary hyperglycemia is associated with poor prognosis, but this factor was not analyzed in this study due to the limited number of cases. Finally, due to the small number of diabetic patients, the role of some special antidiabetic drugs, such as metformin and DPP4 inhibitors, in the process of COVID-19 was not discussed.

\section{Conclusions}

In conclusion, this study revealed poorly controlled diabetes was associated with severe lung lesions as evidenced by certain CT parameters and bad clinical prognosis, and there was a positive correlation between blood glucose level (both HbA1c and FBG) on admission and lung involvement in COVID-19 patients. Moreover, the severity of CT lesions by AI quantitative analysis was correlated with clinical outcomes. Thus, further research is warranted to ascertain whether improved glycemic control correlates with improved outcomes. 
Table 3 Summary of the regression analysis between HbA1c (\%) or FBG (mmol/L) and CT features by AI analysis in COVID-19

\begin{tabular}{|c|c|c|c|c|c|c|c|c|}
\hline & \multicolumn{4}{|c|}{$\operatorname{HbA1c}(n=126)$} & \multicolumn{4}{|l|}{ FBG $(n=126)$} \\
\hline & \multicolumn{2}{|l|}{ Unadjusted } & \multicolumn{2}{|l|}{ Adjusted* } & \multicolumn{2}{|l|}{ Unadjusted } & \multirow{2}{*}{$\begin{array}{l}\text { Adjusted* } \\
\text { B-coefficient }\end{array}$} & \multirow[b]{2}{*}{$p$ value } \\
\hline & B-coefficient & $p$ value & B-coefficient & $p$ value & B-coefficient & $p$ value & & \\
\hline Total lung lesions volume, $\mathrm{cm}^{3}$ & 0.392 & $<0.001$ & 0.330 & 0.003 & 0.361 & $<0.001$ & 0.359 & 0.001 \\
\hline GGO volume, $\mathrm{cm}^{3}$ & 0.381 & $<0.001$ & 0.289 & 0.009 & 0.350 & $<0.001$ & 0.323 & 0.003 \\
\hline Consolidation volume, $\mathrm{cm}^{3}$ & 0.314 & $<0.001$ & 0.437 & $<0.001$ & 0.291 & 0.001 & 0.436 & $<0.001$ \\
\hline Percentage of total lung lesions volume, $\%$ & 0.432 & $<0.001$ & 0.401 & $<0.001$ & 0.413 & $<0.001$ & 0.446 & $<0.001$ \\
\hline Percentage of GGO volume, $\%$ & 0.428 & $<0.001$ & 0.364 & 0.001 & 0.413 & $<0.001$ & 0.421 & $<0.001$ \\
\hline Percentage of consolidation volume, $\%$ & 0.344 & $<0.001$ & 0.472 & $<0.001$ & 0.314 & $<0.001$ & 0.455 & $<0.001$ \\
\hline
\end{tabular}

*Adjusted by age, sex, BMI, and comorbidities

Table 4 Summary of logistic regression analysis and ROC Curve between CT features by AI analysis and composite endpoints

\begin{tabular}{|c|c|c|c|c|c|c|}
\hline & \multicolumn{2}{|l|}{ Unadjusted $(n=126)$} & \multicolumn{2}{|l|}{ Adjusted* $(n=126)$} & \multicolumn{2}{|l|}{ ROC curve $(n=126)$} \\
\hline & OR $(95 \% \mathrm{CI})$ & $p$ value & OR $(95 \% \mathrm{CI})$ & $p$ value & AUC $(95 \% \mathrm{CI})$ & $p$ value \\
\hline Total lung lesions volume, $\mathrm{cm}^{3}$ & $1.002(1.001,1.003)$ & $<0.001$ & $1.002(1.001,1.003)$ & 0.003 & $0.786(0.676,0.897)$ & $<0.001$ \\
\hline GGO volume, $\mathrm{cm}^{3}$ & $1.002(1.001,1.003)$ & $<0.001$ & $1.002(1.000,1.003)$ & 0.008 & $0.774(0.662,0.886)$ & $<0.001$ \\
\hline Consolidation volume, $\mathrm{cm}^{3}$ & $1.007(1.003,1.012)$ & 0.001 & $1.007(1.002,1.012)$ & 0.005 & $0.811(0.716,0.907)$ & $<0.001$ \\
\hline Percentage of total lung lesions volume, $\%$ & $1.067(1.032,1.103)$ & $<0.001$ & $1.057(1.016,1.100)$ & 0.006 & $0.796(0.691,0.900)$ & $<0.001$ \\
\hline Percentage of GGO volume, $\%$ & $1.076(1.034,1.120)$ & $<0.001$ & $1.061(1.013,1.112)$ & 0.013 & $0.783(0.678,0.889)$ & $<0.001$ \\
\hline Percentage of consolidation volume, $\%$ & $1.280(1.110,1.476)$ & 0.001 & $1.269(1.069,1.507)$ & 0.006 & $0.816(0.722,0.911)$ & $<0.001$ \\
\hline
\end{tabular}

Composite endpoints: The primary end point was a composite of death or using mechanical ventilation or admission to intensive care unit

*Logistic regression analysis were adjusted by age, sex, and poorly controlled diabetes

Acknowledgements We greatly appreciate the assistance of Jiazheng Wang (Cancer Research UK Cambridge Institute, Li Ka Shing Centre, Robinson Way, Cambridge, CB2 ORE, UK) in editing and revising the manuscript. We are also grateful for AI technique support provided by Gen Cheng (Shanghai Key Laboratory of Artificial Intelligence for Medical Image and Knowledge Graph, No.523 Louguanshan Road, Changning District, Shanghai, China).

Author contributions Xiaoting Lu, Zhenhai Cui and Lin Li collected the clinical and radiological data. Zhenhai Cui, Feng Pan and Lingli $\mathrm{Li}$ analyzed all the data. Xiaoting Lu and Zhenhai Cui drafted the manuscript. Lian Yang, Liang Bo and Chuansheng Zheng revised the final manuscript.

Funding This study was supported by the Research Fund of Molecular Imaging Key Laboratory, Hubei Province, China (02.03.2015-152).

\section{Compliance with Ethical Standards}

Conflicts of interest The authors declare no conflicts of interest.

Ethical approval The study was approved by the research ethics commission of Wuhan Union Hospital, Tongji Medical College, Huazhong University of Science and Technology (number 2020 0026). This study was conducted in accordance with the 1964 Declaration of Helsinki and its later amendments or comparable ethical standards.
Informed consent The requirement for informed patient consent was waived by the ethics committee for this retrospective study.

\section{References}

1. World Health Organization (2020) Coronavirus Disease 2019 (COVID-19): Situation Report-209. Available.URL https://www. who.int/docs/default-source/coronaviruse/situation-reports/20200 816-covid-19-sitrep-209.pdf?sfvrsn=5dde1ca2_2

2. Yang X, Yu Y, Xu J, Shu H, Xia J, Liu H, Wu Y, Zhang L, Yu Z, Fang M, Yu T, Wang Y, Pan S, Zou X, Yuan S, Shang Y (2020) Clinical course and outcomes of critically ill patients with SARSCoV-2 pneumonia in Wuhan, China: a single-centered, retrospective, observational study. Lancet Respir Med 1:1. https://doi. org/10.1016/S2213-2600(20)30079-5

3. Chen N, Zhou M, Dong X, Qu J, Gong F, Han Y, Qiu Y, Wang J, Liu Y, Wei Y, Xia J, Yu T, Zhang X, Zhang L (2020) Epidemiological and clinical characteristics of 99 cases of 2019 novel coronavirus pneumonia in Wuhan, China: a descriptive study. Lancet (London, England) 395(10223):507-513. https://doi.org/10.1016/ S0140-6736(20)30211-7

4. Guo W, Li M, Dong Y, Zhou H, Zhang Z, Tian C, Qin R, Wang H, Shen Y, Du K, Zhao L, Fan H, Luo S, Hu D (2020) Diabetes is a risk factor for the progression and prognosis of COVID-19. Diabetes Metab Res Rev. https://doi.org/10.1002/dmrr.3319

5. Zhu L, She Z, Cheng X, Qin J, Zhang X, Cai J, Lei F, Wang H, Xie J, Wang W, Li H, Zhang P, Song X, Chen X, Xiang M, Zhang 
C, Bai L, Xiang D, Chen M, Liu Y, Yan Y, Liu M, Mao W, Zou J, Liu L, Chen G, Luo P, Xiao B, Zhang C, Zhang Z, Lu Z, Wang J, Lu H, Xia X, Wang D, Liao X, Peng G, Ye P, Yang J, Yuan Y, Huang X, Guo J, Zhang B, Li H (2020) Association of blood glucose control and outcomes in patients with COVID-19 and pre-existing type 2 diabetes. Cell Metab. https://doi.org/10.1016/j. cmet.2020.04.021

6. Huang C, Wang Y, Li X, Ren L, Zhao J, Hu Y, Zhang L, Fan G, Xu J, Gu X, Cheng Z, Yu T, Xia J, Wei Y, Wu W, Xie X, Yin W, Li H, Liu M, Xiao Y, Gao H, Guo L, Xie J, Wang G, Jiang R, Gao Z, Jin Q, Wang J, Cao B (2020) Clinical features of patients infected with 2019 novel coronavirus in Wuhan, China. Lancet (London, England) 395(10223):497-506. https://doi.org/10.1016/ S0140-6736(20)30183-5

7. Wang D, Hu B, Hu C, Zhu F, Liu X, Zhang J, Wang B, Xiang H, Cheng Z, Xiong Y, Zhao Y, Li Y, Wang X, Peng Z (2020) Clinical characteristics of 138 hospitalized patients with 2019 Novel coronavirus-infected pneumonia in Wuhan, China. JAMA. https ://doi.org/10.1001/jama.2020.1585

8. Wu ZH, Tang Y, Cheng Q (2020) Diabetes increases the mortality of patients with COVID-19: a meta-analysis. Acta Diabetol. https ://doi.org/10.1007/s00592-020-01546-0

9. Guo L, Shi Z, Zhang Y, Wang C, Do VMN, Zuo H, Hussain A (2020) Comorbid diabetes and the risk of disease severity or death among 8807 COVID-19 patients in China: A meta-analysis. Diabetes Res Clin Pract 166:108346. https://doi.org/10.1016/j.diabr es.2020.108346

10. National Health Commission of the People's Republic of China (2020) New coronavirus pneumonia prevention and control program, 7th edn. (in Chinese). Available. URL. http://www.nhc.gov. cn/yzygj/s7653p/202003/46c9294a7dfe4cef80dc7f5912eb1989/ files/ce3e6945832a438eaae415350a8ce964.pdf

11. American Diabetes Association (2020) 2. Classification and diagnosis of diabetes: standards of medical care in diabetes-2020. Diabetes Care 43(Supplement 1):S14-S31. https:// doi.org/10.2337/dc20-S002

12. American Diabetes Association (2020) 6. Glycemic targets: standards of medical care in diabetes-2020. Diabetes Care 43(Suppl 1):S66-S76. https://doi.org/10.2337/dc20-S006

13. Liu F, Zhang Q, Huang C, Shi C, Wang L, Shi N, Fang C, Shan F, Mei X, Shi J, Song F, Yang Z, Ding Z, Su X, Lu H, Zhu T, Zhang Z, Shi L, Shi Y (2020) CT quantification of pneumonia lesions in early days predicts progression to severe illness in a cohort of COVID-19 patients. Theranostics 10(12):5613-5622. https://doi. org/10.7150/thno.45985

14. Ji M, Yuan L, Shen W, Lv J, Li Y, Chen J, Zhu C, Liu B, Liang Z, Lin Q, Xie W, Li M, Chen Z, Lu X, Ding Y, An P, Zhu S, Gao M, Ni H, Hu L, Shi G, Shi L, Dong W (2020) A predictive model for disease progression in non-severe illness patients with Corona Virus Disease 2019. Eur Respir J. https://doi.org/10.1183/13993 003.01234-2020

15. Pan Y, Guan H (2020) Imaging changes in patients with 2019nCov. Eur Radiol. https://doi.org/10.1007/s00330-020-06713-Z

16. Wang Y, Dong C, Hu Y, Li C, Ren Q, Zhang X, Shi H, Zhou M (2020) Temporal changes of CT findings in 90 patients with COVID-19 pneumonia: a longitudinal study. Radiology. https:// doi.org/10.1148/radiol.2020200843

17. Chua F, Armstrong-James D, Desai SR, Barnett J, Kouranos V, Kon OM, José R, Vancheeswaran R, Loebinger MR, Wong J, Cutino-Moguel MT, Morgan C, Ledot S, Lams B, Yip WH, Li L, Lee YC, Draper A, Kho SS, Renzoni E, Ward K, Periselneris J, Grubnic S, Lipman M, Wells AU, Devaraj A (2020) The role of $\mathrm{CT}$ in case ascertainment and management of COVID-19 pneumonia in the UK: insights from high-incidence regions. Lancet Respir Med. https://doi.org/10.1016/S2213-2600(20)30132-6
18. Pan Y, Guan H, Zhou S, Wang Y, Li Q, Zhu T, Hu Q, Xia L (2020) Initial CT findings and temporal changes in patients with the novel coronavirus pneumonia (2019-nCoV): a study of 63 patients in Wuhan, China. Eur Radiol. https://doi.org/10.1007/s00330-02006731-x

19. Liu K, Xu P, Lv W, Qiu X, Yao J, Gu J, Wei W (2020) CT manifestations of coronavirus disease-2019: a retrospective analysis of 73 cases by disease severity. Eur J Radiol 126:108941. https://doi. org/10.1016/j.ejrad.2020.108941

20. Zhang K, Liu X, Shen J, Li Z, Sang Y, Wu X, Zha Y, Liang W, Wang C, Wang K, Ye L, Gao M, Zhou Z, Li L, Wang J, Yang Z, Cai H, Xu J, Yang L, Cai W, Xu W, Wu S, Zhang W, Jiang S, Zheng L, Zhang X, Wang L, Lu L, Li J, Yin H, Wang W, Li O, Zhang C, Liang L, Wu T, Deng R, Wei K, Zhou Y, Chen T, Lau JY, Fok M, He J, Lin T, Li W, Wang G (2020) Clinically applicable ai system for accurate diagnosis, quantitative measurements, and prognosis of COVID-19 pneumonia using computed tomography. Cell. https://doi.org/10.1016/j.cell.2020.04.045

21. Bai HX, Wang R, Xiong Z, Hsieh B, Chang K, Halsey K, Tran T, Choi JW, Wang DC, Shi LB, Mei J, Jiang XL, Pan I, Zeng QH, Hu PF, Li YH, Fu FX, Huang RY, Sebro R, Yu QZ, Atalay MK, Liao WH (2020) AI augmentation of radiologist performance in distinguishing COVID-19 from pneumonia of other etiology on chest CT. Radiology. https://doi.org/10.1148/radiol.2020201491

22. Huang L, Han R, Ai T, Yu P, Kang H, Tao Q, Xia L (2020) Serial quantitative chest CT assessment of COVID-19: deep-learning approach. Radiol Cardiothorac Imaging 2(2):e200075. https://doi. org/10.1148/ryct.2020200075

23. Wang Z, Du Z, Zhu F (2020) Glycosylated hemoglobin is associated with systemic inflammation, hypercoagulability, and prognosis of COVID-19 patients. Diabetes Res Clin Pract 164:108214. https://doi.org/10.1016/j.diabres.2020.108214

24. Raoufi M, Khalili S, Mansouri M, Mahdavi A, Khalili N (2020) Well-controlled vs poorly-controlled diabetes in patients with COVID-19: Are there any differences in outcomes and imaging findings? Diabetes Res Clin Pract 166:108286. https://doi. org/10.1016/j.diabres.2020.108286

25. Iacobellis G, Penaherrera CA, Bermudez LE, Bernal Mizrachi E (2020) Admission hyperglycemia and radiological findings of SARS-CoV2 in patients with and without diabetes. Diabetes Res Clin Pract 164:108185. https://doi.org/10.1016/j.diabr es.2020.108185

26. Holman N, Knighton P, Kar P, O’Keefe J, Curley M, Weaver A, Barron E, Bakhai C, Khunti K, Wareham NJ, Sattar N, Young B, Valabhji J (2020) Risk factors for COVID-19-related mortality in people with type 1 and type 2 diabetes in England: a populationbased cohort study. Lancet Diabetes Endocrinol 8(10):823-833. https://doi.org/10.1016/S2213-8587(20)30271-0

27. Cariou B, Hadjadj S, Wargny M, Pichelin M, Al-Salameh A, Allix I, Amadou C, Arnault G, Baudoux F, Bauduceau B, Borot S, Bourgeon-Ghittori M, Bourron O, Boutoille D, CazenaveRoblot F, Chaumeil C, Cosson E, Coudol S, Darmon P, Disse E, Ducet-Boiffard A, Gaborit B, Joubert M, Kerlan V, Laviolle B, Marchand L, Meyer L, Potier L, Prevost G, Riveline J, Robert R, Saulnier P, Sultan A, Thébaut J, Thivolet C, Tramunt B, Vatier C, Roussel R, Gautier J, Gourdy P (2020) Phenotypic characteristics and prognosis of inpatients with COVID-19 and diabetes: the CORONADO study. Diabetologia 63(8):1500-1515. https:// doi.org/10.1007/s00125-020-05180-x

28. Kulcsar KA, Coleman CM, Beck SE, Frieman MB (2019) Comorbid diabetes results in immune dysregulation and enhanced disease severity following MERS-CoV infection. JCI Insight. https ://doi.org/10.1172/jci.insight.131774

29. Philips BJ, Meguer JX, Redman J, Baker EH (2003) Factors determining the appearance of glucose in upper and lower respiratory 
tract secretions. Intensive Care Med 29(12):2204-2210. https:// doi.org/10.1007/s00134-003-1961-2

30. Fuso L, Pitocco D, Antonelli-Incalzi R (2019) Diabetic lung, an underrated complication from restrictive functional pattern to pulmonary hypertension. Diabetes Metab Res Rev 35(6):e3159. https ://doi.org/10.1002/dmrr.3159
Publisher's Note Springer Nature remains neutral with regard to jurisdictional claims in published maps and institutional affiliations.

\title{
Affiliations
}

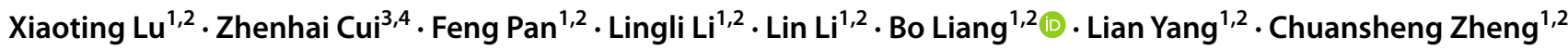

\author{
Bo Liang \\ xiehelb@163.com \\ $\triangle$ Lian Yang \\ yanglian@hust.edu.cn \\ Xiaoting Lu \\ 525651212@qq.com \\ Zhenhai Cui \\ cui13407110019@163.com \\ Feng Pan \\ uh_fengpan@outlook.com \\ Lingli Li \\ lilingli@hust.edu.cn \\ Lin $\mathrm{Li}$ \\ lilin19880418hyj@163.com
}

Chuansheng Zheng

hqzcsxh@sina.com

1 Department of Radiology, Union Hospital, Tongji Medical College, Huazhong University of Science and Technology, Jiefang Avenue \#1277, Wuhan 430022, China

2 Hubei Province Key Laboratory of Molecular Imaging, Wuhan 430022, China

3 Department of Endocrinology, Union Hospital, Tongji Medical College, Huazhong University of Science and Technology, Jiefang Avenue \#1277, Wuhan 430022, China

4 Hubei Provincial Clinical Research Center for Diabetes and Metabolic Disorders, Wuhan 430022, China 